\title{
Review on Traditional Conflict Resolution of Three Selected Ethiopian peoples
}

\author{
Ibsa Aliyi Usmane \\ Department of Rural Development and Agricultural Extension, Haramaya University
}

\begin{abstract}
This article review assessed three Ethiopian ethnic groups traditional conflict resolution that saves life of communities and resources. Among the ethnic groups the Oromo traditional conflict resolution is called Gada system which includes nine members in addition to women conflict resolution known as Ateete/Siiqqee and Araara(reconciliation) that every clans have their own elders who participate in any conflicts raised in communities. The other ethnic groups those solve their conflict in traditional way are Afar people that they resolve conflict in two methods that were intra-and inter clan dispute system by makaban a person who the conflict issues present to him. And also Kambata are people one of the ethnic groups this paper reviewed their conflict resolution were Reeda which elders take part in issue, and Gudagabmela includes curse if the disputants parts refuse to take their decision.
\end{abstract}

Keywords: Conflict, Traditional, Gada System, Makaban, Reeda, Guda gambela

DOI: $10.7176 / \mathrm{JCSD} / 54-03$

Publication date: December $31^{\text {st }} 2019$

\section{Introduction}

Conflict is a common phenomenon and quit frequent in human relation. It is inevitable in any community with different cultural background or within the same ethnic group with the same culture. Conflict can occur between individuals, groups or nations. It can be caused due to the incompatible human need, and the control of scarce resources and the dominance of one on the other (Assefa, 2005:50).

Taking the present situation in Africa, where many countries suffer from disputes of various types, the "Conference on Resolving Disputes in the South African way" which was organized by IDRA (Institute of Dispute Resolution in Africa) held on 5-6 November, 2014 in Pretoria at Kgrong Function Hall, Unisa Main Campus is timely and relevant. There are reports daily that thousands of Africans are suffering from disputes. On the other hand, nowadays, disputes in the African continent are becoming more of a business and way of life to many Western organizations. Until now, Africans have tried to resolve disputes using Western modalities; but practical evidence has already shown that such modalities often aggravate the disputes in Africa and do not resolve them. The author thus congratulates IDRA for taking the initiative of organizing a problem-solving conference that tries to resolve African disputes in an African way. It is the author's strong belief that disputeresolution practices are as old as humans. Thus much can be learned from the dispute-resolution practices of the first Ethiopian people, as Ethiopia is a site of human origin (Kinfe Abraha Gebre-Egziabher, 2014).

\section{Traditional Conflict resolution of three selected Ethiopian peoples}

\subsection{Conflict Resolution in Oromo peoples}

The traditional mechanisms of resolving conflicts and managing natural resources (i.e. water, land and forests) in the Borana zone is derived from the Oromo institutions of gadaa, aadaa, seera and safuu, and the associated cultural administrative structure(Desalegn et al. 2007).

According to the articles I reviewed (Watson, 2001; Dejene, 2004; Desalegn et al., 2007) the conflict resolution of Oromo communities are very large and vast in Gada system, Kallu and siinqee and Ateetee (for women), Jaarsummaa (elders), Gumaa are the major one.

A. Gada System- One major economic function of Gadaa is the distribution of resources by: establishing who had to help whom, when and why, by settling conflicts between families over goods and by making laws. It is the system that governs the Boran's use of natural resources and enables the various groups to coordinate their use of important resources like water. According to gadaa, those people who have entered the Luba grade (individuals in the expected age range of 40-48) are considered to be elders. Therefore, the Lubas (elders) settle disputes among groups and individuals and apply the laws dealing with the distribution of resources, criminal fines and punishment, protection of property, theft, etc.

Thus the elders in the community form a dominant component of the customary mechanisms of conflict management and natural resources management. The foundation of the gadaa system is rooted in the informal or customary Oromo institutions of aadaa (custom or tradition), seera (laws), safuu (or the Oromo concept of Ethics) and heera (justice). Natural resource access is governed by the combination of these different institutions, which are also conflict-resolution institutions and are uniquely placed to assist in tackling the interlinked problems of the environment, welfare, and conflict. The aadaa and seera are rehearsed at a meeting that is held every 8 years 
in Borana. Aadaa sanctions the different strategies that the Boran institutions at all levels adopt and restrict access to those parts of the pasture within their jurisdiction. In Borana Oromo community the conflict resolution can be solved at different level of their traditional starting from Abbaa Gadaa to family level. As I reviewed the article published by Dejene (2007 et. al.) in Gada system the following are bodies responsible for any actions in the society and resolute for any wrongs in communities:

1. Abbaa bokkuu or abbaa gadaa - president.

2. Abbaa bokkuu I - vice-president.

3. Abbaa bokkuu II - vice-president.

4. Abbaa caffee - chairman of the assembly (caffee).

5. Abbaa dubbii - speaker who presents the decision of the presidium to the assembly.

6. Abbaa seeraa - memorizer of the laws and results of the assembly deliberations.

7. Abbaa alangaa - judge who executes decisions.

8. Abbaa duulaa - in charge of the army.

9. Abbaa sa'aa - in charge of the economy.

B. Ateetee and Siiqqee are women's' institutions that they use for their own issues concerned in the Oromo society like conflict resolution, respecting, management of the resources around them and their daily livelihood activities. Ateetee and Siiqqee help women as a way of strengthening their solidarity and as a tool to counter atrocities staged against them by men. Similarly, as a check and balance mechanism, in conflict resolution; and is institutionalized and women form parallel organizations of their own that actively exclude men. This method of conflict resolution is very practical in Arsi Oromo

C. Araara (literal meaning, reconciliation) is another important informal institution with relevance to conflict resolution of Oromo institution and Jaarsummaa (literal meaning, the process of reconciliation between conflicting individuals or groups by a group of Jaarsaas). Dejene 2004 reported the effectiveness of the Araara institution between the Karrayyu Oromo of the Upper Awash and its neighboring ethnic groups like the Afar and Argoba. Araara is the process of conflict management involving individual clans within and outside the community. It is basically handled by the council of elders in the community and thus associated with the gadaa system, and called jaarsummaa in some localities. The term jaarsa is the Oromo version of elder, and thus jaarsummaa, is the process of reconciliation between conflicting individuals or groups by a group of jaarsaas (elders).

\subsection{Traditional Conflict Resolution in Afar peoples}

Kinfe Abraha Gebre-Egziabher (2014) studied and published article on the dispute resolution of the Afar people of Ethiopia elders and clans leaders solve minor disputes in the context of traditional law; in case of the Afar ethnic groups, this system is called mada'a, which is governed by an unwritten law that is transmitted from generation to generation orally. The law is of two types - dispute-resolution laws that concern intra-ethnic group disputes, and laws concerning inter-ethnic group disputes.

\section{A. Procedures to resolve intra-clan dispute}

According to the article published by Kinfe Abraha Gebre-Egziabher (2014) I reviewed disputes that occurs intra-clan usually arise from minor conflicts such as insults and quarrels that may result in bodily injury. Conflict over grazing land and homicide rarely occur between members of the same clan. Any member of a clan who comes across conflict between two or more individuals has the moral obligation to try to reconcile the disputants. If they do not accept the proposal of reconciliation or if the committed crime is grave, the injured party or anyone who witnessed the cause of the dispute can bring the case to the kedo abba of the sub clans or the makaban of a clan, depending on the gravity of the case. The makaban to whom the disputants bring their case selects elders who help him in deciding the case and fixes the place and date of hearing the dispute in the maro. After the elders, disputants, witnesses, if any, and observers are gathered under a tree, the makaban opens the proceedings by requesting the disputant to bring ahabi, who guarantees the good behavior of the disputant and acceptance of the makaban's decision. The habi may be a member of a family or a sub clan chief of the disputants.

After the disputants nominate their habisi [plural form] the makaban gives the plaintiff the first opportunity to explain his case. The plaintiff may do this personally or select a representative, usually a chief of his clan, to speak in his name. Children below the age 15 , or persons who are considered unable to explain their case, are not allowed to give testimony in front of the maro, and must be represented by an elder from their clan or by her husband in a case of married woman. Unless he admits the allegation, the defendant or his representative is given the chance to explain their version of the case after the plaintiff completes his presentation.

After hearing both parties, the makaban may give both parties a chance to rebut, if possible, what their opponents say. If there are witnesses named by the plaintiff the makaban asks them to explain what they know 
about the dispute. If the witness is not present in the maro, the makaban orders him to appear and adjourns the case for other time. The plaintiff or anyone who hears this order informs the witness. The witnesses appear in the maro because they respect the order of the makaban.

Finally, the makabans pronounce the decision in public and the maro is declared closed by the blessing made by an elder. All the proceedings in the maro are carried out in public without regard to the nature of the dispute and the age of parties. This practice is one of the features that differentiate a maro from procedures applicable in a formal court, which may prohibit a public hearing only in exceptional cases and conduct sessions in camera to protect private lives and public morality.

\section{B. Procedures to resolve inter-clan dispute}

When conflict occurs between members of different clans, the makaban of one of the disputant clans bring his case to the makaban of a neutral clan before the conflict can cause serious damage; in the case of inter-clan homicide, the intention is to resolve the issue amicably before the clan of the deceased can seek revenge. If the issue is not resolved members of a deceased's clan are duty-bound to kill any member of the offender's clan, including an innocent person, in vengeance. A prominent personality whose death would hurt the clan of the offender is usually selected as the victim.

The makaban of the neutral clan announces to both parties the date of the hearing and orders both parties not to take any measures that can harm the amicable resolution of the case. Both parties, and members of the injured clan, are expected to refrain from taking vengeance and respect the words of the makaban. Depending on the gravity of the case, the makaban may ask the help of other makabans of different (neutral) clans and select elders from different clans to resolve the dispute brought to him. Makabans of disputant clans represent their clans and explain their version of the disputed issue to the makabans of the neutral clan.

\subsection{Traditional conflict Resolution in Kambata communities}

According to the article published by Abebe Demewoz Mengesha, Samson Seid Yesuf, and Tessema Gebre (2015) conflicts in Kambata, as in anywhere else, may vary from trivial interpersonal disagreements to a serious dispute which might eventually lead to homicide. The most common conflict issues in Kambata are grazing land, water, farmland and borderland. There are many deeds and accounts in the daily activities of the society which are considered to be crimes vis-à-vis the norms and traditions of the Kembata community. However, the most serious ones are: beating a man with a slump and/or thin stick, beating elderly, raping, murder, physical damage, adultery.

According to the above article I reviewed the traditional conflict resolution of Kamabata peoples are:

A. Reeda $=$ Reeda takes in charge of solving conflicts issues. So as these institutions can intervene and calm the situation created between the two parties by finding ways as to how the people from the side of the deceased stop their revenge. This is because such institutions are usually considered as being neutral, as they are the make ups of different clans of Kambata, as a result of which they would not favor one party over the other.

B. Gudagambela $=$ it implies declaring or concluding something or an event not to happen again. The tradition has complex ritual procedures and strong symbolic representation of purification of the 'curse' and reconciliation of conflicting individuals/groups. The Gudagambela tradition is performed not only as a mechanism of purifying the 'curse' from the guilty but also as a method of conflict resolution. Through the ritual processes, the guilty and his clans would be reconciled with the relatives and clan of the offended. The tradition works both in resolution of inter-personal as well as inter-group conflicts.

\section{Conclusion and Recommendation}

\subsection{Conclusion:}

From this reviewed articles in Ethiopia conflict resolution is very essential and heart of the country's economic development which can stabilize the security and peace of the people, contributes the sustainable development and growth the country has to achieve within specified time. Still Ethiopia is known by its peace and secured country in Africa as model and peoples reside in the country has the culture of living with in diversity and respect with one another. The conflict which retard back the country's economy, peace and security of the country can resolute in traditional form in every part of communities for example in the referred article Oromo, Afar and Kambata communities have long history of cultural conflict resolution in their contextual society and areas. Almost all the traditional conflict resolution of these communities is structurally arranged system and does not contradict with the statuary judicial system of the country.

\subsection{Recommendation:}

From the above conclusion of reviewed articles the country's policy makers and other stakeholders should better to strengthen these institutions according to their needs and interest of the communities, leaders and elders in their contextual areas and society, since these institutions have their own role and contribute more in this plan and sustain it to ensure the economic development and growth, peace and security the country planned with in 
gaze of achieving the middle income country.

\section{References}

Abebe, Demewoz, Mengesha, Samson Seid Yesuf, and Tessema Gebre, "Indigenous Conflict Resolution Mechanisms among Kembata Society." American Journal of Educational Research, vol. 3, no. 2 (2015): 225-242. doi: 10.12691/education-3-2-17.

Dejene, A. (2004) Fuzzy access rights in pastoral economies: case studies from Ethiopia. The Tenth Biennial Conference of the International Association for the Study of Common Property,

Desalegn et al.CAB International 2007. Community-based Water Law and Water Resource Management Reform in Developing Countries (eds B. van Koppen, M. Giordano and J. Butterworth) page, 146.

Kinfe Abraha Gebre-Egziabher: Dispute resolution mechanisms among the Afar People of Ethiopia and their contribution to the Development Process: TD The Journal for Transdisciplinary Research in Southern Africa, 10(3) December 2014, pp. 152-164.

Assefa Abebe. 2005. "Indigenous Mechanisms for Prevention and Resolution of Conflict: The Experience of the Oromo".In Proceedings of Second National Workshop of Ethiopian Chapter of OSSREA. Addis Ababa. Pp, 50-70

Watson, E. (2001) Inter Institutional Alliances and Conflicts in Natural Resources Management: Preliminary Research Findings from Borana, Oromiya region, Ethiopia. Marena Research Project. Working Paper No. 4, Department for International Development, UK.

Workneh, K. (2001) Traditional Oromo Attitudes towards the Environment: an Argument for Environmentally Sound Development. Social Science Research Report Series, No. 19, OSSREA, Addis Ababa, Ethiopia. 